\title{
Idiopathic membranous nephropathy in pediatric patients: presentation, response to therapy, and long-term outcome Ashton Chen ${ }^{1}$, Rachel Frank ${ }^{1}$, Suzanne Vento ${ }^{1}$, Virginia Crosby ${ }^{1}$, Manju Chandra ${ }^{1}$, Bernard Gauthier ${ }^{1}$, Elsa Valderrama ${ }^{2}$ and Howard Trachtman*1
}

\begin{abstract}
Address: ${ }^{1}$ Department of Pediatrics, Division of Nephrology, Schneider Children's Hospital of North Shore-Long Island Jewish Health System New Hyde Park, NY 11040-1432, USA and 2Department of Pathology, Schneider Children's Hospital of North Shore-Long Island Jewish Health System, New Hyde Park, NY 11040-1432, USA

Email: Ashton Chen - ashtonchendo@aol.com; Rachel Frank - rfrank@lij.edu; Suzanne Vento - svento@lij.edu; Virginia Crosby - vcrosby@nshs.edu; Manju Chandra - mchandra@nshs.edu; Bernard Gauthier - bernardggauthier@msn.com;

Elsa Valderrama - evalderr@lij.edu; Howard Trachtman* -trachtma@lij.edu

* Corresponding author
\end{abstract}

Published: 6 August 2007

BMC Nephrology 2007, 8:II doi:10.1186/147I-2369-8-II

This article is available from: http://www.biomedcentral.com/I47I-2369/8/II

(c) 2007 Chen et al; licensee BioMed Central Ltd.

This is an Open Access article distributed under the terms of the Creative Commons Attribution License (http://creativecommons.org/licenses/by/2.0), which permits unrestricted use, distribution, and reproduction in any medium, provided the original work is properly cited.

\begin{abstract}
Background: Idiopathic membranous nephropathy (IMN) is one of the most common causes of primary nephrotic syndrome in adults. However, it is a relatively rare entity in the pediatric population and there is a paucity of data about the incidence, prognosis, and optimal treatment of IMN in children and adolescents. We conducted this study to evaluate pediatric patients with IMN in order to clarify the presentation, response to therapy, and clinical outcome.
\end{abstract}

Methods: A retrospective chart review was performed on patients identified with biopsy-proven IMN between 1988-2005. Patients with systemic lupus erythematosus or hepatitis-related lesions were excluded. The following data were tabulated: age, gender, ethnicity, presenting clinical and laboratory findings, proteinuria in a first morning urine specimen, estimated glomerular filtration rate $\left(G_{F}\right)$, histopathology, type and duration of treatment, and clinical status at final evaluation.

Results: 13 cases of IMN were identified out of 460 renal biopsies performed for evaluation of primary kidney disease during the study interval. Mean age was $9.6 \pm 4.6$, gender $6 \mathrm{M}: 7 \mathrm{~F}$, ethnicity $8 \mathrm{~W}: 2 \mathrm{~B}: 3 \mathrm{H}$. At the initial visit hematuria was present in 9 patients, edema in 5, nephrotic-range proteinuria in 5 , and hypertension in 3 . Mean urinary protein:creatinine ratio $3.3 \pm 2.5$ and all patients had a normal GFR . Classic glomerular findings of IMN were seen in all renal specimens, with concomitant interstitial changes in 2 cases. Treatment included an angiotensin converting enzyme inhibitor or angiotensin receptor blocker in II cases. Most patients were also given immunosuppressive medications - prednisone in 10, a calcineurin inhibitor in 5 , and mycophenolate mofetil or azathioprine in 3 patients. At the last follow-up, $42 \pm 35$ months after the diagnostic biopsy, 7 children were hypertensive and the urine protein:creatinine ratio was $2.3 \pm 3.1$. The mean $\mathrm{GFR}_{\mathrm{e}}$ was $127 \pm 57 \mathrm{~mL} / \mathrm{min} / \mathrm{m}^{2}$. Three patients had Chronic Kidney Disease Stage 3, all of whom were also hypertensive.

Conclusion: IMN is a rare but serious glomerulopathy in pediatrics. We estimate that it accounts for approximately $3 \%$ of renal biopsies. Long-term prognosis is guarded because approximately $50 \%$ of patients may have evidence of progressive kidney disease. 


\section{Background}

Although idiopathic membranous nephropathy (IMN) is one of the most common etiologies of nephrotic syndrome in adults, it is an uncommon entity in the pediatric population [1]. When it is identified in childhood, membranous nephropathy is often a result of co-morbid illnesses, such as SLE, hepatitis B or C infection, or administration of various medications [1]. After excluding these secondary causes, IMN is extremely rare. There is a paucity of data about the prognosis and optimal treatment of IMN in children and adolescents. Therefore, we conducted this single-site, retrospective review of IMN in children and adolescents to clarify these unresolved issues.

\section{Methods}

A retrospective chart review was performed on all patients identified with biopsy-proven idiopathic membranous nephropathy (IMN) at Schneider Children's Hospital between 1988-2005. Patients were identified by scanning a database maintained in the Division of Nephrology. They were eligible for inclusion in this study if they had histopathological findings consistent with IMN. Patients with SLE, hepatitis, or any other secondary causes were excluded based on history and negative laboratory studies. Pathology records were reviewed to determine the number of renal biopsies done during the study period for the evaluation of potential primary kidney disease.

The following data at initial presentation were recorded: age, gender, ethnicity, clinical and laboratory findings, estimated glomerular filtration rate $\left(\mathrm{GFR}_{e}\right)$, and histopathology based on renal biopsy. Ethnicity was classified in accordance with NIH guidelines. Clinical findings noted at presentation included height, weight, and blood pressure, and presence or absence of edema. Laboratory findings included BUN, serum creatinine, albumin, and cholesterol concentrations, hematuria (defined as positive if the reading was more than trace), and urine protein:creatinine ratio in a first morning specimen. Nephrotic-range proteinuria was defined as a ratio $>2$. GFR ${ }_{e}(\mathrm{~mL} / \mathrm{min} / 1.73$ $\mathrm{m}^{2}$ ) was calculated using the age-appropriate Schwartz formula [2]. Chronic kidney disease (CKD) was classified according to the NKF/DOQI guidelines [3]. Blood pressures were evaluated using the 2004 National High Blood Pressure Education Program Working Group guidelines, based on gender, age, and height percentiles [4]. The summaries of the histopathology findings were obtained from the pathological report. The presence or absence of interstitial disease, the predominant immunoglobulin deposited in subepithelial space, and presence of glomerular sclerosis were noted.

For each patient, the type of medication and the total duration of therapy were recorded. At the final follow-up visit, the same data set extracted at the time of the disease presentation was recorded.

Information was gathered using a pre-approved form and data were deidentified and recorded by study number in accordance with HIPAA guidelines. This retrospective chart review was approved by the Institutional Review Board of the North Shore-Long Island Jewish Health System.

Data are presented as mean \pm SD. The difference between groups was evaluated using the Student t-test. Differences in outcome between groups defined by the presence or absence of specific clinical findings at presentation were assessed using the Fisher exact test. Results were considered statistically significant if the $P$ value was less than 0.05 .

\section{Results}

Over the 17-year study period, 13 patients with biopsyproven IMN were identified (Table 1). The mean age at presentation was $9.6 \pm 4.6$ years (range: $4-17$ years), and 9 patients were $\leq 10$ years old. Six patients were male. Eight patients were White, 2 patients were Black, and 3 were of Hispanic ethnicity. When they were first evaluated, 9 patients had microscopic hematuria, 5 had peripheral edema, 5 had nephrotic-range proteinuria, and 3 patients were hypertensive. Less common symptoms were abdominal pain noted in 2 patients and nocturnal enuresis in 1 patient. At presentation, all patients had a normal serum creatinine concentration and the $\mathrm{GFR}_{e}$ was 155 $\pm 34 \mathrm{~mL} / \mathrm{min} / 1.73 \mathrm{~m}^{2}$. No patient had a reduced GFR $_{e^{\prime}}$ i.e., $<90 \mathrm{~mL} / \mathrm{min} / 1.73 \mathrm{~m}^{2}$. Six patients had hypoalbuminemia and all 13 patients had hypercholesterolemia. The urinary protein:creatinine ratio at the initial assessment was $3.3 \pm 2.5$. (Table 1 )

Table I: IMN in pediatric patients: clinical and laboratory data $(\mathbf{N}=13)$

\begin{tabular}{|c|c|c|}
\hline & $\begin{array}{c}\text { Initial Visit } \\
\mathbf{N}(\%)\end{array}$ & $\begin{array}{c}\text { Final Visit } \\
\text { n (\%) }\end{array}$ \\
\hline Mean Age & $9.6 \pm 4.6$ & -- \\
\hline Gender & $6 \mathrm{M}: 7 \mathrm{~F}$ & -- \\
\hline Ethnicity & $8 \mathrm{~W}: 2 \mathrm{~B}: 3 \mathrm{H}$ & -- \\
\hline Hematuria & $9(69 \%)$ & $6(46 \%)$ \\
\hline Peripheral Edema & $5(38 \%)$ & 0 \\
\hline $\begin{array}{l}\text { Proteinuria (protein:creatinine } \\
\text { ratio) }\end{array}$ & $3.3 \pm 2.5$ & $2.3 \pm 3.1$ \\
\hline Nephrotic-range Proteinuria & $5(38 \%)$ & $3(23 \%)$ \\
\hline Hypoalbuminemia & $6(46 \%)$ & $5(38 \%)$ \\
\hline Hypertension & $3(23 \%)$ & 7 (54\%) \\
\hline Hypercholesterolemia & $10(77 \%)$ & $5(38 \%)$ \\
\hline GFR $\mathrm{mL} / \mathrm{min} / \mathrm{m}^{2}$ & $155 \pm 34$ & $127 \pm 57$ \\
\hline CKD Stage 3-5 & 0 & $3(23 \%)$ \\
\hline
\end{tabular}

Abbreviations: CKD, Chronic kidney disease; $\mathrm{GFR}_{\mathrm{e}}$, Estimated glomerular filtration rate 
The mean interval between referral to pediatric nephrology and performance of a kidney biopsy was $1.7 \pm 1.5$ months. Characteristic histopathological findings of IMN were seen in glomeruli in all specimens. Three patients were identified as having glomerulosclerosis, 2 of whom also had tubulointerstitial disease. Precise staging was done in only 4 patients with 3 patients classified a Stage II and 1 as Stage III. Eleven patients had subepithelial deposits on biopsy, 8 had intramembranous changes, and 2 had resorption of deposits. Diffuse or localized podocyte fusion was noted in 11 patients. The predominant immunoglobulin in the subepithelial or intramembranous deposits was IgG in all 12 patients for whom this information was recorded. Of these, 2 had combined IgG and IgM and 1 had IgG and IgA deposition.

Eleven out of the 13 patients received an angiotensin converting enzyme inhibitor (ACEI) or angiotensin receptor blocker (ARB) for $20 \pm 21$ months. Ten patients were also given immunosuppressive therapy with prednisone as the first-line therapy. The criteria for the use of prednisone were persistence of proteinuria after implementation of treatment with ACEI and/or ARB. The initial dosage of prednisone was $60 \mathrm{mg} / \mathrm{m}^{2} /$ day for 4-6 weeks followed by $40 \mathrm{mg} / \mathrm{m}^{2}$ every other day. The duration of prednisone treatment was $16 \pm 19$ months and the medication was discontinued without tapering. Six of the patients went on to receive one or more second-line drugs: cyclosporine (n $=3)$, tacrolimus $(\mathrm{n}=2)$, and/or mycophenolate mofetil/ azathioprine $(n=3)$. There were no consistent criteria or clinical guidelines for the administration of these agents during the study period. The cumulative duration of secondary immunosuppressive therapy was cyclosporine 22 \pm 12 months, tacrolimus $11 \pm 2$ months, and mycophenolate mofetil/azathioprine $15 \pm 16$ months. Proteinuria fluctuated over the course of treatment without clear-cut relapses or remissions. Figure 1 summarizes the overall changes in treatment during the follow-up period.

At last follow-up, $42 \pm 35$ months after the diagnostic biopsy, none of the patients had peripheral edema, 6 had hematuria, 5 had hypoalbuminemia, and 4 were hypertensive. In the complete cohort the $\mathrm{GFR}_{e}$ was $127 \pm 57 \mathrm{ml} /$ $\min / 1.73 \mathrm{~m}^{2}$ and the urine protein:creatinine ratio was $2.3 \pm 3.1$ (Table 1). Although these values were lower than original levels, the changes were not significant $(P>0.15)$. 3 patients had an elevated serum creatinine concentration with a GFR $e_{e}$ of $37 \pm 9 \mathrm{~mL} / \mathrm{min} / 1.73 \mathrm{~m}^{2}$ (CKD Stage 3), compared with the remaining patients who had a $\mathrm{GFR}_{e}$ $157 \pm 22 \mathrm{~mL} / \mathrm{min} / 1.73 \mathrm{~m}^{2}$.

None of the following clinical features at initial presentation - hematuria, nephrotic-range proteinuria, or hypertension - had any predictive value in determining which patients would develop hypertension or compromised

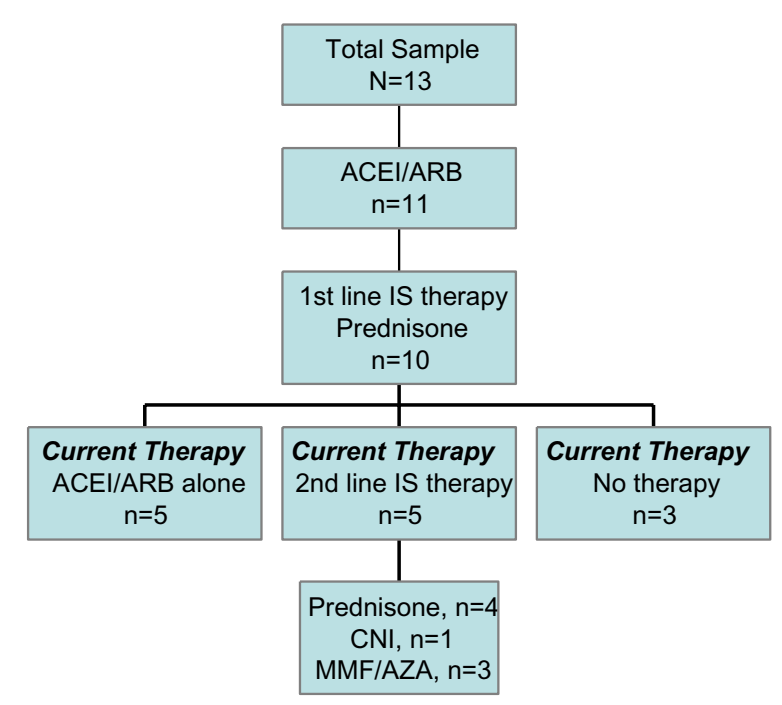

Abbreviations: ACEI, angiotensin converting enzyme inhibitor; ARB, angiotensin receptor CNI, calcineurin inhibitor; IS, immunosuppressive drug; MMF, mycophenolate mofetil

\section{Figure I}

Summary of treatment provided to the patients with IMN.

GFR during the follow-up period, reflecting the small sample size. Nonetheless, it is worth noting that all 3 patients with hypertension at the onset of the disease had $\mathrm{CKD}$ and remained hypertensive at the last follow-up visit.

\section{Discussion}

In this single center retrospective review, we describe 13 cases of IMN identified over a 17 year time period. Based on a total of 715 renal biopsies done during the study period, we estimate that the likelihood of a patient who undergoes this procedure for evaluation of glomerular disease having IMN is approximately $2 \%$. Although IMN is a rare disease in the pediatric population, it can occur in the first decade of life as illustrated by our finding that 9 out of the 13 cases were documented in children less than 10 years of age. Males and females are equally affected and the disease occurred in all ethnic groups. The predominance of white patients (62\%), compared to Blacks (15\%) and Hispanics $(23 \%)$, reflects the demographics of our institution. Nonetheless, the gender and ethnic distribution in our series is similar to other reports of the disease in children and adolescents [5].

The patients with IMN presented with varied signs and symptoms, most commonly hematuria $(75 \%)$, proteinuria $(50 \%)$, and edema $(38 \%)$, consistent with other publications [5]. Patients may have hypoalbuminemia but 
most have hypercholesterolemia. The reason for the dissociation between the changes in serum albumin and cholesterol is unclear. All patients had normal renal function, but nearly a quarter had hypertension at the time of diagnosis.

In our study, histopathological staging of IMN in the renal biopsies was not standard procedure [6]. There are several reports in the literature indicating that in adults this procedure is helpful in predicting prognosis and the response to drug therapy [7,8]. In children, Ramirez, et al [9] reported an increased likelihood of progression to renal insufficiency with Stage III and IV on initial biopsy compared to Stage I or II lesions. However, Latham P et al [10] described no correlation between initial histological staging and clinical outcome. Obana et al [11] recently reported segmental versus diffuse glomerular involvement and proposed that these patterns may represent two disease entities or subcategories of IMN. However, staging was not evaluated as a prognostic tool in this article.

There is a great deal of discussion about the nature and duration of treatment for IMN in adult patients without a clear consensus on the most appropriate therapeutic choice [12]. Prednisone is the standard first-line immunosuppressive therapy for IMN in pediatric patients and steroid-resistant disease is the usual indication to initiate treatment with another immunosuppressive agent. It is difficult to assess the efficacy of the second-line immunosuppressive drugs prescribed in our study because these medications were only initiated after the patient was refractory to prednisone. Thus, bias may be introduced based on administration to those who were refractory to steroids and who may have had more severe kidney disease. In addition, we are unable to compare efficacy between mycophenolate mofetil, azathioprine, cyclosporine, and tacrolimus because the small number of patients in our study precludes such an analysis. Moreover, some patients received two or more second-line agents. This reflects the infrequent occurrence of IMN in pediatrics and the single center nature of this report. A collaborative randomized clinical trial will almost certainly be required to evaluate efficacy of immunosuppressive medications in children and adolescents with IMN.

ACEI and/or ARB therapy are renoprotective in adult patients with glomerular disease. We are unable to compare outcomes in patients receiving ACEI or ARB therapy versus those who did not, because only two patients were not treated with one of these antihypertensive agents. If these drugs are used alone, they may be insufficient to adequately control blood pressure or retard disease in patients with IMN. Thus, other antihypertensive medications should be prescribed to control blood pressure in addition to maximum tolerated antiproteinuric doses of ACEI and/or ARB therapy, given the increased incidence of hypertension that we observed during the follow-up period.

At the time of the final assessment, the mean $\mathrm{GFR}_{\mathrm{e}}$ decreased from initial presentation, with 3 patients $(23 \%)$ having CKD Stage 3, described as moderate decrease in $\mathrm{GFR}_{\mathrm{e}}$ [3]. These three patients were also hypertensive and were the same three patients who presented with hypertension at the onset of their disease. Moreover, 4 other patients developed hypertension with maintenance of normal GFR . Thus, there was an increased proportion of patients with hypertension from $23 \%$ at initial presentation to $54 \%$ at last the follow-up visit. In spite of immunosuppressive therapy, involving more than one class of drug in some patients, IMN can be a progressive disease in children and adolescents.

In the last three decades, there have been 7 other reports of IMN in children that contained at least 10 patients. (Table 2) Most estimate an occurrence rate of IMN between $1.0-6.7 \%$ of all renal biopsies performed at their institution [9-11,13-16], which is consistent with our observations. They all confirm that the disease can occur in children $<10$ years old. The gender distribution ranges

Table 2: Prior reports of IMN in pediatric patients: a comparative review

\begin{tabular}{|c|c|c|c|c|c|c|c|c|c|}
\hline Author, Year & $\mathbf{N}$ & $\underset{(y r)}{\text { Follow-up }}$ Period & $\begin{array}{c}\text { Mean Age at } \\
\text { Presentation (yr) }\end{array}$ & Age Range & M:F & $\begin{array}{c}\text { Nephrotic at } \\
\text { Presentation (\%) }\end{array}$ & $\begin{array}{c}\downarrow \text { GFR at } \\
\text { last F/U (\%) }\end{array}$ & $\begin{array}{c}\text { HTN at } \\
\text { last F/U (\%) }\end{array}$ & $\begin{array}{c}\text { Estimated } \\
\text { Occurrence } \\
\text { Rate (\%) }\end{array}$ \\
\hline Habib et al., 1973 & 50 & $1-10$ & NA & $8 \mathrm{mo}-14 \mathrm{yr}$ & $38: 12$ & 62 & 10 & NA & 3.7 \\
\hline Trainin et al., 1976 & 14 & 5.5 & 9 & $2-15 y r$ & $6: 8$ & 79 & 29 & NA & 6.7 \\
\hline Ramirez et al., 1982 & 22 & 4.7 & 12 & $11 \mathrm{mo}-19.9 \mathrm{yr}$ & $|1: 1|$ & 77 & 37 & NA & 5.7 \\
\hline Latham et al., 1982 & 14 & 6.4 & 10.5 & $3.5-14$ & $9: 5$ & 79 & 21 & NA & 1.3 \\
\hline Tsukahara et al., 1993 & 12 & 5.9 & 7.7 & $2.9-15.8 \mathrm{yr}$ & $8: 4$ & 25 & 0 & 0 & 3 \\
\hline Obana et al., 2006 & 38 & $\begin{array}{c}7.5 \text { (SMGN); } 12.4 \\
(\text { GMGN) }\end{array}$ & 7.6 & $1.5-16 \mathrm{yr}$ & $25: 13$ & 24 & 0 & $5 \%$ & 2.4 \\
\hline Lee et al., 2006 & 19 & 28.5 & 9.5 & $1.7-14.9$ & $9: 10$ & 89.5 & 15 & NA & 1 \\
\hline Current study & 13 & 3.5 & 9.6 & $4-17 y r$ & $6: 7$ & 38 & 23 & $54 \%$ & 2.8 \\
\hline
\end{tabular}

Abbreviations: GMGN, global membranous glomerulonephritis; HTN, hypertension; NA, not available; SMGN, segmental membranous glomerulonephritis 
from an even split as in our series $[9,15,16]$ to a male predominance $[10,11,13,14]$. There is wide variability in the percentage of patients presenting with nephrotic-range proteinuria, as well as the degree of long-term renal morbidity. Our outcome data are most similar to Latham et al [10] and Trainin et al [15] who reported that $21-29 \%$ of patients manifested renal insufficiency at the last followup. Most studies in adult patients with IMN suggest that at least a quarter progress to CKD [17]. The presence of hypertension alone at last follow-up in 4 out of our 13 patients, an observation not routinely reported in the pediatric studies, raises additional concerns about the prognosis in those patients. It is worth noting that in Latham's study [10], children with IMN who had hypertension at the onset of their disease had a lower likelihood of entering remission. The marked variability in outcome in pediatric patients with IMN may depend on differences in ethnicity, biopsy practice patterns, and genetic factors. This argues in favor of exercising caution when discussing prognosis with individual pediatric patients found to have IMN.

\section{Conclusion}

In summary, (1) IMN is a rare disease in childhood accounting for approximately $3 \%$ of all biopsies done in pediatric patients; (2) The long-term prognosis of IMN should be considered guarded because nearly $50 \%$ of patients will have CKD and/or hypertension after a 4 year follow-up period; and (3) Although prednisone is the current mainstay of immunosuppressive therapy, systematic evaluation of the efficacy of other immunosuppressive drugs in children and adolescents with IMN is urgently required building on the experience of randomized clinical trials performed in adult patients $(18,19,20,21,22)$. The rarity of IMN in pediatrics limits its study and the challenge of identifying optimal treatment will mandate a collaborative approach.

\section{Abbreviations}

ACEI: angiotensin converting enzyme inhibitor

ARB: angiotensin receptor blocker

CKD: chronic kidney disease

GFRe: estimated glomerular filtration rate

HTN: hypertension

IMN: idiopathic membranous nephropathy

SLE: systemic lupus erythematosus

\section{Competing interests}

The author(s) declare that they have no competing interests.

\section{Authors' contributions}

$\mathrm{AC}, \mathrm{RF}, \mathrm{SV}, \mathrm{MC}, \mathrm{BG}$, and $\mathrm{HT}$ designed the retrospective data collection form. $\mathrm{AC}, \mathrm{RF}, \mathrm{SV}$, and $\mathrm{VC}$ collected the data. AC, HT, MC and BG analyzed the data. AC, HT and $\mathrm{BG}$ wrote the manuscript. EV reviewed the renal biopsies and summarized the pathology data.

\section{Acknowledgements}

This study was presented in part at the annual meeting of the Society for Pediatric Research, San Francisco, CA, May 2006.

\section{References}

I. Kaplan BS, Meyers KE: Pediatr Nephrol Urol 2004, 4(23): I 79-I8I.

2. Hogg RJ, Furth S, Lemley KV, Portman R, Schwartz GJ, Coresh J, Balk E, Lau J, Levin A, Kausz AT, Eknoyan G, Levey AS: National Kidney Foundation's Kidney Disease Outcomes Quality Initiative Clinical Practice Guidelines for Chronic Kidney Disease in Children and Adolescents: Evaluation, Classification, and Stratification. Pediatr 2003, I I I:|4|6-|421.

3. K/DOQI :Clinical Practice Guidelines for Chronic Kidney Disease: evaluation, classification, and stratification. Am J Kidney Dis 2002, 39:SI-246.

4. National high blood pressure education program working group: The Fourth Report on the Diagnosis, Evaluation and Treatment of High Blood Pressure in Children and Adolescents. Pediatr 2004, I | 4:555-576.

5. Avner ED, Harmon WE, Niaudet P: Pediatric Nephrology 5th edition. 2004:643-645.

6. Ehrenreich T, Churg J: Pathology of membranous nephropathy. Pathol Ann 1968, 3: I45-186.

7. Polenakovik MH, Greevska L: Treatment and long-term followup of patients with stage II to III idiopathic membranous nephropathy. Am J Kidney Dis 1999, 34:911-917.

8. Marx BE, Marx M: Prediction in idiopathic membranous nephropathy. Kidney Int 1999, 56:666-673.

9. Ramirez F, Brouhard BH, Travis LB, Ellis EN: Idiopathic membranous nephropathy in children. J Pediatr 1982, I 0 I:677-68I.

10. Latham P, Poucell S, Koresaar A, Arbus G, Baumal R: Idiopathic membranous glomerulopathy in Canadian children: a clinicopathologic study. J Pediatr 1982, I 0 I:682-685.

II. Obana M, Nakanishi K, Sako M, Yata N, Nozu K, Tanaka R, lijima K, Yoshikawa N: Segmental Membranous Glomerulonephritis in Children: Comparison with Global Membranous Glomerulonephritis. Clin J Am Soc Nephrol 2006, I:723-729.

12. Lai KN: Membranous nephropathy: when and how to treat. Kidney Int 2007, 7 I:84I-843.

13. Habib R, Kleinknecht C, Gubler MC: Extramembranous glomerulonephritis in children: report of $\mathbf{5 0}$ cases. J Pediatr 1973, 82:754-66.

14. Tsukahara H, Tasua T, Masahiro Y, Hayashi S, Fujisawa S, Suehiro F, Akaishi K, Nomura Y, Morikawa K, Sudo M: Clinical course and outcome of idiopathic membranous nephropathy in Japanese children. Pediatr Nephrol 1993, 4:387-91.

15. Trainin EB, Boichis H, Spitzer A, Greifer I: Idiopathic membranous nephropathy: Clinical course in children. New York State J Med 1976, 76:357-360.

16. Lee B, Cho H, Kang H, Ha H, Cheong H, Moon K, Lim I, Choi Y: Idiopathic membranous nephropathy in children. Pediatr Nephrol 2006, 2 I : I707-I7| 5.

17. Troyanov S, Roasio L, Pandes M, Herzenberg AM, Cattran DC: Renal pathology in idiopathic membranous nephropathy: A new perspective. Kidney Int 2006, 69: I64I-I648.

18. Sterling CM, Simpson K, Boulton-Jones JM: Immunosuppression and outcome in idiopathic membranous nephropathy. $Q J$ Med 1998, 91:159-164.

19. Fujimoto S, Hara S, Sato Y, Yamada K, Kisanaga S: Nephrotic syndrome caused by membranous nephropathy: response to 
short course cyclophosphamide alternating with prednisolone. Intern Med 2004, 1:30-34.

20. Ponticelli C, Altieri P, Scolai F, Passerini P, Roccatello D, Cesana B, Melis P, Valzorio B, Sasdelli M, Pasquali S, Pozzi C, Piccoli G, Lupo A, Segagni S, Antonucci F, Dugo M, Minari M, Scalia A, Pedrini L, Pisano G, Grassi C, Farina M, Bellazzi R: A randomized study comparing methylprednisolone plus chlorambucil versus methylprednisolone plus cyclophosphamide in idiopathic membranous nephropathy. J Am Soc Nephrol 1998, 9(3):444-450.

21. Ponticelli C, Passerini P, Salvadori M, Manno C, Viola BF, Pasquali S, Mandolfo S, Messa P: A 10 year follow-up of a randomized study with methylprednisolone and chlorambucil in membranous nephropathy. Kidney Int 1604, 48:1600-1995.

22. Ponticelli C, Passerini P, Salvadori M, Manno C, Viola BF, Pasquali S, Mandolfo S, Messa P: A randomized pilot trial comparing methylprednisolone plus a cytotoxic agent versus synthetic adrenocorticotropic hormone in idiopathic membranous nephropathy. Am J Kidney Dis 2006, 47:233-240.

\section{Pre-publication history}

The pre-publication history for this paper can be accessed here:

http://www.biomedcentral.com/1471-2369/8/11/prepub

Publish with Bio Med Central and every scientist can read your work free of charge

"BioMed Central will be the most significant development for disseminating the results of biomedical research in our lifetime. "

Sir Paul Nurse, Cancer Research UK

Your research papers will be:

- available free of charge to the entire biomedical community

- peer reviewed and published immediately upon acceptance

- cited in PubMed and archived on PubMed Central

- yours - you keep the copyright

Submit your manuscript here:

http://www.biomedcentral.com/info/publishing_adv.asp 